\title{
Investigating the causal relationship between employment and informal caregiving of the elderly
}

(a) CrossMark

\author{
Edel Walsh * (1) and Aileen Murphy (1)
}

\begin{abstract}
Objective: Examining the causal relationship between employment and informal caring to date has been impeded in countries like Ireland where there is a lack of suitable panel data and/or variables for instrument construction. This paper employs propensity score matching to control for non-random selection into treatment and control groups which controls for differences in employment outcomes between carers and non-carers in Ireland using data from Quarterly National Household Survey 2009 Quarter 3. Earlier papers focus on using regression techniques which may lead to biased estimates.

Results: Results suggest that differences exist between carers and non-carers with respect to their employment status in Ireland. Overall the results suggest that the effects are more significant for those providing greater hours of informal care per week than those providing fewer hours of care per week. The effects estimated in this paper are likely to be more precise as failing to account for potential biases in the relationship are likely to underestimate the true effect of caring on employment outcomes. We find that propensity score matching provides an alternative method of examining the relationship when suitable panel data and/or variables for instrument construction are not available.
\end{abstract}

Keywords: Informal care, Employment, Propensity score matching

\section{Introduction}

As well as being preferred by older people themselves and favourable for the public purse, informal care has been demonstrated to be a substitute for formal long-term care [1-4]. However, there are concerns as to whether supply will meet anticipated demands [2]. Supply of carers is restricted by social and economic changes such as increased female labour force participation, delayed retirements and migration, as well as changing family structures including smaller families, decreased coresidency of elderly with their children and the decline in traditional marriages. Therefore, it is feared a global shortage may arise $[5,6]$. Previous research demonstrated that co-residential informal care does compete with other

\footnotetext{
*Correspondence: e.walsh@ucc.ie

Department of Economics, Cork University Business School, University College Cork, Cork, Ireland
}

activities such as employment and childcare [7]. This is unsurprising given that informal carers are more likely to be women [8], who are married and have lower levels of education [9].

The relationship between informal caring and carers' employment or labour market outcomes is complex, and despite extensive research ambiguity remains [10]. While results are varied, the majority of research concludes that caregiving exerts modest negative pressure on the likelihood of formal employment and hours worked, suggesting a trade-off between caring and working [2, 8, 10-12]. Recent research has found varying effects by age [13], gender and occupation [14, 15]. Dealing with this causal relationship between formal employment and informal caregiving is a recurring challenge in the literature. A variety of methods, including instrumental variables $[10$, 16-19]; difference in difference approaches [20]; simultaneous equation models $[21,22]$; reduced form equations 
[23]; discrete time survival models [24] have been utilised to estimate the relationship between informal care and employment. However, employing these methods are dependent on data availability to construct instruments and/or utilising panel data. So, in countries like Ireland, where there is a lack of suitable panel data and/or variables for instrument construction, examining the causal relationship between employment and informal caring is impeded.

Leigh [25] attests that if it were possible to demonstrate if all carers were relieved of their caring duties would they have the same employment rate as non-carers, then cross sectional studies could provide unbiased estimates of the casual impact of caring on paid employment. This paper investigates Leigh's [25] proposal and employs propensity score matching to determine if differences in employment outcomes between carers and non-carers exist in Ireland, where it is expected that by 2041 over $22 \%$ of the population will be over 65 years of age.

\section{Main text \\ Data}

The data used for this study is obtained from the Quarterly National Household Survey $2009(n=21,542)$. The Carers Module was a special module included in Quarter 3 of this survey, the focus of which was on those providing care (the 'carer') rather than those receiving care (the 'dependent'). The data specifically asks about caring informally (unpaid) for others; that care being provided to anyone who has a long-term physical or mental illness or disability or problems related to old age. Given that we are interested in elder care provision, we confine our analysis to those providing care to individuals aged 65 and over and exclude the remaining carers $(n=578)$.

Table 1 presents the proportion of observations falling within each category for the full sample $(n=20,964)$. All respondents were asked about their employment status and the categories indicated if an individual is in paid employment (50\%), unemployment (8\%), or economically inactive (40\%). The latter group includes students (4.2\%), homemakers (21.3\%), sick (3.5\%), other-unspecified $(0.5 \%)$ and those that are retired $(12.2 \%)$. Since providing care is unlikely to affect the employment outcomes of this cohort they are excluded from our analyses. $6 \%$ of the full sample were carers and of those $57 \%$ provided less than $15 \mathrm{~h}$ of care per week and $43 \%$ care for $15 \mathrm{~h}$ or more per week.

\section{Methods}

This paper examines how hours of informal caring affect labour force participation. Owing to the fact that the relationship between these two variables is likely to be endogenous, regression techniques, such as ordinary least squares (OLS), may not be suitable in addressing the relationship. As an alternative we employ matching estimators to investigate if any differences exist with respect to labour force participation between groups of carers and non-carers, taking into account the hours of caring undertaken. Thus, we examine if all carers were relieved of their caring duties would they have the same probability of being employed as their non-carer counterparts. Propensity score matching techniques are based on the idea of comparing the outcomes of people that are as similar as possible with the sole exception of their treatment status. In this case 'treatment status' is whether the individual is a carer or not and the 'outcome' is employment status. More specifically, the analysis looks at caring (distinguishing between caring for more or less than $15 \mathrm{~h}$ per week) and employment status (employed or unemployed) to fully estimate the relationship between caring and labour force participation.

The type of propensity score matching used in this analysis is nearest neighbor matching. Here the individual from the comparison group (a non-carer) is chosen as a matching partner for a treated individual (a carer providing more than/less than $15 \mathrm{~h}$ of care per week) that is closest in terms of propensity score. The propensity score is defined as the conditional probability of receiving the treatment given the independent variables. Propensity score methods normally comprise four major steps [26]. Firstly, a propensity score is estimated for each unit using a probit regression of treatment conditions on covariates. Secondly, each unit in the treatment group is matched with one or more units in the comparison group based on the closest distance between their propensity scores. At this stage the balancing property must be satisfied. Thirdly, estimate the matching quality and finally, estimate the intended outcome analysis on the matched data or on the original data with propensity score adjustment or weighting [26]. The nearest-neighbor matching estimator calculates the average treatment effect (ATT) and the average treatment effect on the treated (ATET).

The matching procedure requires that the outcome variable (employment status), must be independent of treatment (caring) conditional on the propensity score [27]. Therefore, using matching requires choosing a set of independent variables (Xs) that satisfy this condition. Only variables that influence simultaneously the participation decision and the outcome variable should be included [28]. If $\mathrm{P}(\mathrm{X})=0$ or $\mathrm{P}(\mathrm{X})=1$ for some values of $\mathrm{X}$ matching cannot be used on those $\mathrm{X}$ values to estimate a treatment effect because individuals with such characteristics either always or never receive a treatment. According to Heckman et al. [29] some randomness is needed that guarantees that persons with identical characteristics can be observed in both states. To satisfy this 
Table 1 Descriptive statistics (Source QNHS, Q3, CSO (2009))

\begin{tabular}{|c|c|c|}
\hline Variables & Description of variables & N (\%) \\
\hline \multicolumn{3}{|l|}{ Caring variables } \\
\hline Carer & 1 if engaged in informal caring duties, 0 if not caring & $1394(6)$ \\
\hline$<15 \mathrm{~h} /$ week & 1 if caring for less than $15 \mathrm{~h}$ per week, 0 if not caring & $798(4)$ \\
\hline$>15 \mathrm{~h} /$ week & 1 if caring for more than $15 \mathrm{~h}$ per week, 0 if not caring & $539(3)$ \\
\hline Care $15 \mathrm{~h}$ & 1 if caring for more than $15 \mathrm{~h}$ per week, 0 if caring for less than $15 \mathrm{~h}$ per week & $596(43)$ \\
\hline \multicolumn{3}{|c|}{ Employment status } \\
\hline Employed & 1 if employed, 0 otherwise & $10,447(50)$ \\
\hline Unemployed & 1 if unemployed, 0 otherwise & $1741(8)$ \\
\hline \multicolumn{3}{|c|}{ Personal characteristics } \\
\hline Female & 1 if female, 0 if male & $12,360(58)$ \\
\hline Under 25 & 1 if under 25 years old, 0 otherwise & $3353(16)$ \\
\hline Age $25-44$ & 1 if between 25 and 44 years old, 0 otherwise & $8714(42)$ \\
\hline Age 45-64 & 1 if between 45 and 64 years old, 0 otherwise & $6122(29)$ \\
\hline Over 65 & 1 if over 65 years old, 0 otherwise & $2775(13)$ \\
\hline \multicolumn{3}{|l|}{ Education level } \\
\hline Primary & 1 if primary school level only completed, 0 otherwise & $4332(21)$ \\
\hline Second level & 1 if secondary school level completed, 0 otherwise & $7509(36)$ \\
\hline Post sec & 1 if post-secondary/third level education completed, 0 otherwise & $9123(43)$ \\
\hline \multicolumn{3}{|l|}{ Marital status } \\
\hline Never married & 1 if single/never married, 0 otherwise & $6663(32)$ \\
\hline Married & 1 if married, 0 otherwise & $11,314(54)$ \\
\hline Widowed & 1 if widowed, 0 otherwise & $1652(8)$ \\
\hline Divorced & 1 if divorced, 0 otherwise & $466(2)$ \\
\hline Separated & 1 if separated, 0 otherwise & $868(4)$ \\
\hline \multicolumn{3}{|l|}{ Region in Ireland } \\
\hline Border & 1 if living in the Border region, 0 otherwise & $2263(11)$ \\
\hline Mideast & 1 if living in the Mideast, 0 otherwise & $2219(11)$ \\
\hline Midland & 1 if living in the Midlands, 0 otherwise & $1108(5)$ \\
\hline Midwest & 1 if living in the Midwest, 0 otherwise & $2079(10)$ \\
\hline Southeast & 1 if living in the Southeast, 0 otherwise & $2353(11)$ \\
\hline Southwest & 1 if living in the Southwest, 0 otherwise & $3842(18)$ \\
\hline West & 1 if living in the West, 0 otherwise & $2036(10)$ \\
\hline Dublin & 1 if living in Dublin, 0 otherwise & $5064(24)$ \\
\hline
\end{tabular}

$\mathrm{N}=20,964$. Categorical variables have a minimum value of 0 and a maximum value of 1

condition several control variables are used in the analysis (specifically; gender, age, educational achievement, marital status and region) which may affect both the probability of providing informal care and employment status, respectively.

\section{Results}

The probit estimates of care hours, which are used to calculate the propensity scores, are presented in Additional file 1: Table S1. These results suggest that participation in the treatment (being a carer) is significantly associated with a number of personal and socio-economic characteristics. The balancing property is satisfied for all matching estimates. The matching results are presented in Table 2. The results vary by hours of informal care provided and by outcome (labour force participation).

The matching results show significant differences in employment outcomes between carers who care for more than $15 \mathrm{~h}$ per week and non-carers. The treatment effects are statistically significant across the employment outcomes suggesting that caring for more than $15 \mathrm{~h}$ per week has a significant effect on an individual's probability of being in employment or unemployed (actively seeking work). The ATT coefficient between caring and employment is negative and significant, suggesting that caring for more than $15 \mathrm{~h}$ has a negative impact on an 
Table 2 Propensity score nearest neighbour matching

\begin{tabular}{|c|c|c|c|c|}
\hline \multirow[t]{2}{*}{ Outcome } & \multicolumn{2}{|l|}{ More than $15 \mathrm{~h}$ care/week } & \multicolumn{2}{|l|}{ Less than $15 \mathrm{~h}$ care/week } \\
\hline & $\begin{array}{l}\text { Number of observations treated } \\
\text { (controls) }\end{array}$ & ATT (Std. Err ${ }^{\mathrm{a}}$ ) & $\begin{array}{l}\text { Number of observations treated } \\
\text { (controls) }\end{array}$ & ATT (Std. Err*) \\
\hline Employed & $539(12,309)$ & $-0.050(0.020)^{* * *}$ & 798 (16125) & $0.022(0.017)$ \\
\hline Unemployed & $539(12,309)$ & $-0.014(0.010)^{*}$ & $798(16125)$ & $0.002(0.009)$ \\
\hline
\end{tabular}

Table 3 Propensity score nearest neighbour matching

\begin{tabular}{llc}
\hline Outcome & \multicolumn{2}{l}{ Hours of caring per week (more than $\mathbf{1 5} \mathrm{h}$ ) } \\
\cline { 2 - 3 } & $\begin{array}{l}\text { Number of observations } \\
\text { treated (controls) }\end{array}$ & ATT (Std. Err ${ }^{\mathrm{a}}$ ) \\
\hline Employed & $596(692)$ & $-0.111(0.029)^{* * *}$ \\
Unemployed & $596(692)$ & $0.007(0.014)$ \\
\hline
\end{tabular}

Average treatment effects on the treated (ATT). The numbers of treated and controls refer to actual nearest neighbour matches. Treatment $(\mathrm{T})$ is carer hours $>15 \mathrm{~h} \mathrm{p} / \mathrm{w}(1)>15 \mathrm{~h} \mathrm{p} / \mathrm{w}(0)$. Outcome $(\mathrm{Y})$ is employed $(1,0)$, unemployed $(1,0)$. Independent variables are gender, age, education, marital status, region (the variables 'postsec' and 'southwest' are dropped to satisfy the balancing property)

*** Significant at the $1 \%$ level, ** Significant at the $5 \%$ level, * Significant at the $10 \%$ level

a Bootstrapped standard errors

individual's probability of being in employment (compared with not being a carer). Similarly, compared with being a non-carer, the ATT on unemployment is negative and significant (10\% level) suggesting a negative relationship between caring for more than $15 \mathrm{~h}$ and those in unemployment (i.e. individuals seeking employment).

For those caring less than $15 \mathrm{~h}$ per week the balancing property is again satisfied however, results are insignificant. Overall, the results suggest that the effects are more significant for those providing greater hours of informal care per week than those providing fewer hours of care per week. The effects estimated in this paper are likely to be more precise given the potential biases in the relationship that are likely to underestimate the true effect of caring on employment outcomes.

The matching procedure is then carried out to control for differences in carers that care for more than $15 \mathrm{~h}$ per week and those caring for less than $15 \mathrm{~h}$ per week. More specifically, we are now comparing employment outcomes for groups of carers rather than comparing with non-carers. The results are presented in Table 3 .

The ATT coefficient between hours of caring ( $>15 \mathrm{~h}$ per week) and employment is negative and significant, suggesting that caring for more than $15 \mathrm{~h}$ has a negative impact on an individual's probability of being in employment (compared with those caring for less than $15 \mathrm{~h}$ per week). We do not find a significant effect between caring and unemployment for different groups of carers.

\section{Discussion}

A link between employment status and hours of informal care is established $[10,11,16,17,21-23]$. The usual techniques for handling the relationship between informal care and employment require panel data or construction of instruments. When these are not available investigating this link is difficult. This study illustrates when only cross sectional data is available, a matching estimator can be utilised to address the link between employment decisions and informal care provision across the two groups (carers and non-carers).

In this study the results differ across outcome (employed/unemployed) and treatment (care hours). The matching estimators are statistically significant for the employed and the unemployed which suggests that differences exist between carers of the elderly ( $>15 \mathrm{~h}$ per week) and non-carers with respect to their employment outcomes. Further analyses confirm that differences also exist between groups of carers. Specifically between carers who care for more than $15 \mathrm{~h}$ per week and those that care for less than $15 \mathrm{~h}$ per week.

\section{Conclusion}

As the demand for elder care increases, informal carers appear to be a "cheap" solution from the perspective of the health and social care budgets to elder care [1]. However relying on informal care requires informal carers, the supply of which are limited and unsustainable [2]. Thus, in planning for the future, the causal relationship between employment and informal caregiving needs to be examined. Such an investigation on a per country basis is important as the relationship between caring and employment is not consistent across countries owing to background and local structures [30]. To date such analyses has required panel data and/or variables for 
instrument construction. While data collection systems and efforts are improving, such data is not always available. This paper investigates Leigh's [25] proposal that if it were possible to demonstrate if all carers were relieved of their caring duties would they have the same employment probability as non-carers, then cross sectional studies could provide unbiased estimates of casual impact of caring on paid employment. We find that propensity score matching provides an alternative method of examining the relationship when suitable panel data and/or variables for instrument construction are not available.

\section{Limitations}

We acknowledge the data employed in this study is from 2009. However, the carers' module has not been included in subsequent Quarterly National Household Budget Surveys; and the more recent Irish Longitudinal Study on Ageing (TILDA) data is confined to those over 50 years of age. Therefore the data represents the best available and is suitable for investigating the feasibility of using propensity score matching as alternative method of examining the relationship between caring and employment.

\section{Additional file}

Additional file 1. Probit estimates of the probability of hours of informal care provided per week (used in the calculation of the propensity scores).

\section{Abbreviations}

ATT: average treatment effect (ATT); ATET: average treatment effect on the treated (ATET)

\section{Authors' contributions}

EW and AM have contributed to the conception and planning of the work, analysis and interpretation of data and drafting the manuscript. EW and AM have read and approved the manuscript. Both authors read and approved the final manuscript.

\section{Acknowledgements}

The authors would like to acknowledge useful comments received on earlier drafts of this paper from delegates at the ISPOR 18th Annual European Congress meeting and the European Health Economics Association (EuHEA) Conference 2016.

\section{Competing interests}

The authors declare that they have no competing interests.

\section{Availability of data and materials}

The data that support the findings of this study are available from Irish Social Science Data Archive (ISSDA) but restrictions apply to the availability of these data, which were used under license for the current study, and so are not publicly available. Data are however available from the authors upon reasonable request and with permission of ISSDA.

\section{Consent for publication}

Not applicable.

\section{Ethics approval and consent to participate}

This article does not contain any studies with human participants or animals performed by any of the authors.

Funding

No funding has been received for this work.

\section{Publisher's Note}

Springer Nature remains neutral with regard to jurisdictional claims in published maps and institutional affiliations.

Received: 2 May 2018 Accepted: 4 August 2018

Published online: 10 August 2018

\section{References}

1. Bolin K, Lindgren B, Lundborg P. Informal and formal care among singleliving elderly in Europe. Health Econ. 2008;17(3):393-409.

2. Carmichael F, Charles S, Hulme C. Who will care? Employment participation and willingness to supply informal care. J Health Econ. 2010:29(1):182-90.

3. Van Houtven $\mathrm{CH}$, Norton EC. Informal care and health care use of older adults. J Health Econ. 2004;23(6):1159-80.

4. Viitanen TK. Informal and formal care in Europe. 2007

5. Tarricone R, Tsouros AD. Home care in Europe: the solid facts. Copenhagen: WHO Regional Office Europe; 2008.

6. Francesca C, Ana LN, Jérôme M, Frits T. OECD health policy studies help wanted? Providing and paying for long-term care: providing and paying for long-term care, vol. 2011. Paris: OECD Publishing; 2011.

7. Mentzakis E, McNamee P, Ryan M. Who cares and how much: exploring the determinants of co-residential informal care. Rev Econ Household. 2009;7(3):283-303.

8. Carmichael F, Charles S. The opportunity costs of informal care: does gender matter? J Health Econ. 2003;22(5):781-803.

9. McGee HM, Molloy G, O'Hanlon A, Layte R, Hickey A. Older people-recipients but also providers of informal care: an analysis among community samples in the Republic of Ireland and Northern Ireland. Health Soc Care Community. 2008;16(5):548-53.

10. He D, McHenry P. Does formal employment reduce informal caregiving? Health Econ. 2015;25:829-43.

11. Van Houtven $\mathrm{CH}$, Coe NB, Skira MM. The effect of informal care on work and wages. J Health Econ. 2013;32(1):240-52.

12. Løken KV, Lundberg S, Riise J. Lifting the burden: formal care of the elderly and labor supply of adult children. J Human Resour. 2017:52(1):247-71.

13. Yeandle S, Buckner L. Older workers and care-giving in England: the policy context for older workers' employment patterns. J Cross Cult Gerontol. 2017;32(3):303-21.

14. Trong NH, Connelly LB. The dynamics of informal care provision in an Australian household panel survey: previous work characteristics and future care provision. Econ Rec. 2017;93(302):395-419.

15. Ciccarelli N, Van Soest A. Informal caregiving, employment status and work hours of the $50+$ population in Europe. De Econ. 2018;166(3):363-96.

16. Bolin K, Lindgren B, Lundborg P. Your next of kin or your own career?: Caring and working among the $50+$ of Europe. J Health Econ. 2008;27(3):718-38.

17. Nizalova O. The wage elasticity of informal care supply: evidence from the health and retirement study. South Econ J. 2012;79(2):350-66.

18. Stern S. Estimating family long-term care decisions in the presence of endogenous child characteristics. J Human Resour. 1995;30(3):551-80.

19. Nguyen HT, Connelly LB. The effect of unpaid caregiving intensity on labour force participation: results from a multinomial endogenous treatment model. Soc Sci Med. 2014;100:115-22.

20. Goldbergstein E. The effects of women's employment incentives on their co-residence with older, disabled parents. In: Essays on long-term care and aging. PhD dissertation, University of Michigan. 2008.

21. Boaz RF. Full-time employment and informal caregiving in the 1980s. Med Care. 1996;34(6):524-36. 
22. Doty $P$, Jackson ME, Crown W. The impact of female caregivers' employment status on patterns of formal and informal eldercare. Gerontologist. 1998;38(3):331-41.

23. Michaud P-C, Heitmueller A, Nazarov Z. A dynamic analysis of informal care and employment in England. Labour Econ. 2010;17(3):455-65.

24. Carr E, Murray ET, Zaninotto P, Cadar D, Head J, Stansfeld S, Stafford M. The association between informal caregiving and exit from employment among older workers: prospective findings from the UK Household Longitudinal Study. J Gerontol Ser B. 2016. https://doi.org/10.1093/geron b/gbw156.

25. Leigh A. Informal care and labor market participation. Labour Econ. 2010;17(1):140-9.
26. Pan W, Bai H. Propensity score interval matching: using bootstrap confidence intervals for accommodating estimation errors of propensity scores. BMC Med Res Methodol. 2015;15(1):53.

27. Caliendo J, Kopeinig S. Some practical guidance for the implementation of propensity score matching. J Econ Surv. 2008;22(1):31-72.

28. Heckman J, Ichimura H, Todd P. Matching as an econometric evaluation estimator: evidence from evaluating a job training programme. Rev Econ Stud. 1997;64(4):605-54.

29. Heckman J, Ichimura H, Todd P. Matching as an econometric evaluation estimator. Rev Econ Stud. 1998;65(2):261-94.

30. Henz U. Informal caregiving at working age: effects of job characteristics and family configuration. J Marriage Fam. 2006;68(2):411-29.
Ready to submit your research? Choose BMC and benefit from:

- fast, convenient online submission

- thorough peer review by experienced researchers in your field

- rapid publication on acceptance

- support for research data, including large and complex data types

- gold Open Access which fosters wider collaboration and increased citations

- maximum visibility for your research: over $100 \mathrm{M}$ website views per year

At BMC, research is always in progress.

Learn more biomedcentral.com/submissions 